\title{
Indigenizing food sovereignty
}

\author{
Review by David W. Everson, University \\ of Southern Maine*
}

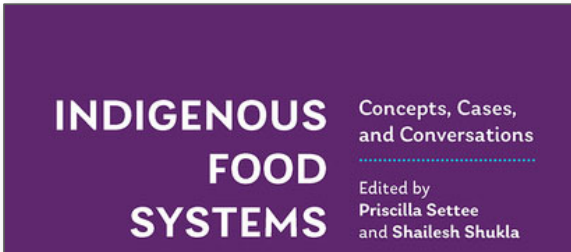

Review of Indigenous Food Systems: Concepts, Cases, and Conversations, edited by Priscilla Settee and Shailesh Shukla. (2020). Canadian Scholars. Available as paperback and eBook; 292 pages. Publisher's book page: https://www.canadianscholars.ca/subjects/indigenousstudies/books/indigenous-food-systems

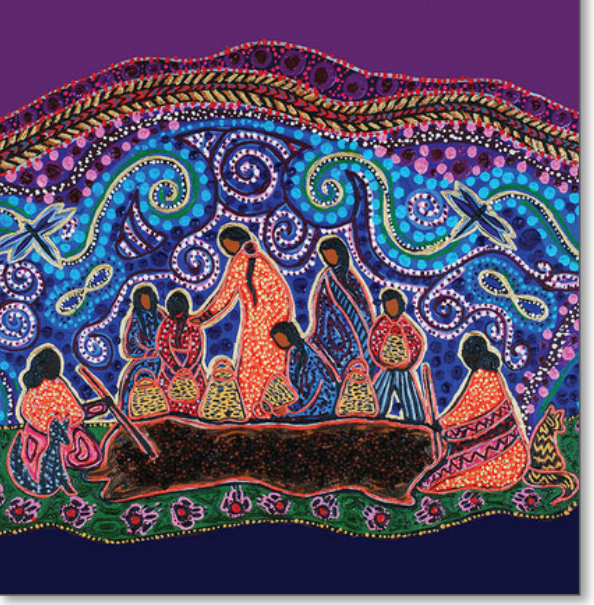

Submitted August 14, 2020 / Published online October 26, 2020

Citation: Everson, D. W. (2020). Indigenizing food sovereignty [Book review].

Journal of Agriculture, Food Systems, and Community Development, 10(1), 273-275.

https://doi.org/10.5304/jafscd.2020.101.021

Copyright (C) 2020 by the Author. Published by the Lyson Center for Civic Agriculture and Food Systems. Open access under CC-BY license.

$I^{\prime}$

t has been nearly 25 years since the international peasants' movement La Via Campesina outlined a "food sovereignty" framework at the 1996 World Food Summit. Since that time, the broader food sovereignty movement continues to accelerate, drawing renewed attention as the escalating climate crisis and global pandemic lay bare the corporate food system's production of environmental and racial injustices. Despite its institutionalization in a growing number of academic food studies programs, however, food sovereignty's theorization

* David W. Everson is an assistant professor of sociology at the University of Southern Maine. His research focuses on settler colonialism and Indigenous social movements. He is a research fellow with the Center for American Indian Research and Native Studies. He can be contacted at david.everson@maine.edu and praxis continue to be shaped in contexts typically absent of Indigenous voices. This is a starkly ironic reality considering that corporate food systems in settler-colonial societies like Canada and the United States are enabled by the ongoing hoarding of Indigenous ecological resources.

Such reasons underscore the importance and timeliness of Indigenous Food Systems: Concepts, Cases, and Conversations. In assembling a diverse collection of scholar-practitioners, Priscilla Settee and Shailesh Shukla have produced an edited volume notable in both form and content. Bracketed by Settee and Shukla's decades of research and activism on the subject, the book's 15 chapters provide an accessible overview of the complexities of Indigenous food sovereignty in Canada. Beyond its 
theoretical and empirical insights, the inclusion of within-chapter pedagogical tools, including critical thinking questions, concept glossaries, and suggested readings, make the text an invaluable resource for instructors.

\section{Section I of Indigenous Food Systems (Chapters} 2-5) foregrounds the distinctiveness of Indigenous food sovereignty by contrasting dominant cultural understandings of food sovereignty and food security. In regards to the former's focus on the localized control over food production and distribution, Morrison (Chapter 2) sets out four principles of Indigenous food sovereignty: (1) the sacredness of food, (2) active participation in traditional land and water-based foodways, (3) self-determination, and (4) sovereignty over public policy. Indigenous food sovereignty, in short, attempts to reconnect the social, cultural, spiritual, and ecological relationships that were severed by settler colonialism in order to achieve Indigenous well-being, an outcome attainable only if Canada's Indigenous communities have unimpeded access to their traditional lands and waters. Dawson (Chapter 5) distinguishes the idea of Indigenous well-being from the Eurocentric conceptualization of health focused on individual "nutrition," as evinced by Canada's official Food Guide. The broader social and cultural connections of food systems to individual and collective Indigenous well-being is also emphasized by Levi (Chapter 3) and Pawlowska-Mainville (Chapter 4). Levi documents how interviews with members of the Elsipogtog First Nation in New Brunswick yielded holistic understandings of food security, ultimately leading to a range of ongoing initiatives that include community gardens and the community sharing of traditionally harvested foods. In contrast, Pawlowska-Mainville utilizes collaborative research with the Poplar River First Nation in northern Manitoba to emphasize both the diversity of Indigenous food systems (also see Chapter 13) and how the foodways of the Canadian boreal forest deviate from the agrocentric focus of dominant food sovereignty discourse.

Although community-based initiatives are invoked throughout the book, section II (Chapters 6-10) devotes five chapters to case studies of applied research with Indigenous peoples, including those living in urban spaces. In Chapter 10,
Kouri, Engler-Stringer, Thomson, and Wood detail the social and kinship-based networks that facilitate Indigenous foodways in inner-city Saskatoon. By consuming both market-based and traditional foods (the latter often procured through an "alternative food network" rooted in cultural principles of sharing), urban-based Indigenous peoples resist food insecurity while concurrently maintaining a connection to land-based practices. The notion of Indigenous food sovereignty being "grounded in the land and rooted in an epistemology of relationships" (p. 144) is similarly emphasized by Martens and Cidro's (Chapter 8) community-based research in inner-city Winnipeg. By participating in yearlong food workshops that incorporated a range of traditional harvesting practices (e.g., gardening, ice fishing), Indigenous youth in the city's North End neighborhood gained practical skills while "demonstrat [ing] the power and potential of working together as part of a cultural experience to strengthen Indigenous cultures" (p. 146).

The final section (Chapters 11-15) highlights contemporary challenges to Indigenous food systems, further contextualizing settler colonialism's ongoing threats to First Nation and Métis livelihoods in Canada. Thompson and Pritty (Chapter 11) document how a lack of running water, inadequate sewage systems, and food price inflation contribute to food insecurity in the O-Pipon-Na-Piwin Cree Nation (OPCN) in northern Manitoba. Severed from their land base by the provincial Churchill River Diversion hydroelectric project in 1976, the OPCN represents a common case of how colonial development produces Indigenous food insecurity. OPCN resistance has included community-based collaborations such as the Ithinto Mechisowin Program (IMP), which mobilizes the knowledge and practices of Elders to harvest and distribute traditional food (Chapter 7 also discusses IMP). Programs such as the IMP have shown promise in reducing food insecurity over the last decade. In contrast to the ongoing displacements resulting from development projects and climate change (see Chapter 12), Neufeld (Chapter 14) focuses on the cultural destruction resulting from Canada's residential school system. Through interviews with First Nation female elders in southwestern Ontario, the author documents 
how residential schools severed the ecological, social, and cultural ties of Indigenous women, including the silencing of the intergenerational transmission of land-based food practices.

By tying together historical context, conceptualizations of Indigenous food sovereignty, and applied community-based case studies, Indigenous Food Systems accomplishes a great deal in the span of a single edited volume. As such, it is recommended for scholars and practitioners across a range of subjects, such as food studies, public health, applied sociology, and Indigenous studies. Its lessons on the interconnection of humanecological rootedness and well-being should resound with both Indigenous and non-Indigenous communities alike. 